\title{
REVIEW
}

\section{HIV Treatment with the Two-Drug Regimen Dolutegravir Plus Lamivudine in Real-world Clinical Practice: A Systematic Literature Review}

\author{
Rickesh Patel (D) - Lee Evitt · Ilias Mariolis · Simona Di Giambenedetto • Antonella d'Arminio Monforte • \\ José Casado · Alfonso Cabello Úbeda · Laurent Hocqueloux · Clotilde Allavena · Tristan Barber • \\ Diwakar Jha · Rahul Kumar · Rahul Dinesh Kamath · Tia Vincent · Jean van Wyk · Justin Koteff
}

Received: June 9, 2021 / Accepted: August 4, 2021 / Published online: August 24, 2021

(c) The Author(s) 2021

\section{ABSTRACT}

The two-drug regimen dolutegravir plus lamivudine demonstrated durable efficacy for up to 3 years in phase III studies and a high barrier to

Supplementary Information The online version contains supplementary material available at https:// doi.org/10.1007/s40121-021-00522-7.

R. Patel $(\bowtie) \cdot$ L. Evitt · T. Vincent · J. van Wyk ViiV Healthcare, 980 Great West Road, Brentford TW8 9GS, Middlesex, UK

e-mail: rickesh.x.patel@viivhealthcare.com

I. Mariolis

ViiV Healthcare, Athens, Greece

S. Di Giambenedetto

UOC Malattie Infettive, Fondazione Policlinico Universitario Agostino Gemelli IRCCS, Rome, Italy

S. Di Giambenedetto

Dipartimento di Sicurezza e Bioetica, Sezione di Malattie Infettive, Università Cattolica del Sacro Cuore, Rome, Italy

A. d'Arminio Monforte

Department of Health Sciences, Clinic of Infectious Diseases, 'San Paolo' Hospital, University of Milan, Milan, Italy

J. Casado

Hospital Universitario Ramón y Cajal, Madrid, Spain resistance in treatment-naive and virologically suppressed people with HIV (PWH). This systematic literature review summarizes real-world evidence evaluating effectiveness and safety of dolutegravir plus lamivudine. We searched Ovid MEDLINE $^{\circledR}$, Embase $^{\circledR}$, PubMed, Cochrane

A. Cabello Úbeda

Infectious Diseases Division, Fundación Jimenez Diaz University Hospital, Madrid, Spain

\section{Hocqueloux}

Infectious Diseases Department, Centre Hospitalier Régional d'Orléans, Orléans, France

\section{Allavena}

Infectious Diseases Department, CHU Hôtel-Dieu, Nantes, France

T. Barber Royal Free London NHS Foundation Trust, London, UK

D. Jha $\cdot$ R. Kumar $\cdot$ R. D. Kamath GlaxoSmithKline Knowledge Centre, Gurgaon, Haryana, India

J. Koteff ViiV Healthcare, Research Triangle Park, NC, USA 
library, and relevant international conference proceedings from 2013 to 2020. Qualitative synthesis of virologic suppression at Week 48, treatment-emergent resistance, discontinuation rates, and comorbidities was undertaken, with no statistical analyses conducted. Linked publications and potential for duplication in reporting of outcomes for cohorts and populations were identified, and the publication reporting the highest number of $\mathrm{PWH}$ receiving dolutegravir plus lamivudine was included in the analysis. Thirty-four studies reporting on cohorts of PWH not suspected to be linked or to include duplicate data receiving dolutegravir plus lamivudine were identified $(N=5017)$. Of 3744 virologically suppressed $\mathrm{PWH}$ who switched to dolutegravir plus lamivudine, 603 $(16 \%)$ reported history of virologic failure. Nineteen studies included effectiveness data $(n=3558)$, four of which included data from treatment-naive PWH $(n=69)$. In studies with $>100 \mathrm{PWH}$, high rates of virologic suppression (Week 48, 97-100\%) were maintained with dolutegravir plus lamivudine, with low rates of virologic failure $(0-3.3$ per 100 personyears of follow-up); one instance of emergent integrase strand transfer inhibitor resistance was reported in a complex treatment-experienced individual. Rates of discontinuation due to adverse events were low and consistent with previously observed trial data. Dolutegravir plus lamivudine minimally impacted renal function and had minimal impact on or improved lipid profiles and bone mineral density. This systematic review demonstrates that effectiveness and safety of doutegravir plus lamivudine in clinical practice support data from randomized controlled trials with regard to high rates of virologic response, low rates of discontinuation, and a high barrier to resistance.

Keywords: Dolutegravir; Dual therapy; HIV-1 infection; Lamivudine; Real-world

\section{Key Points}

The two-drug regimen dolutegravir plus lamivudine has demonstrated durable efficacy and a high barrier to resistance in phase III clinical trials with data up to 3 years, and this review summarizes data on the effectiveness and safety of dolutegravir plus lamivudine in real-world settings.

Virologic suppression was achieved and maintained with dolutegravir plus lamivudine in a wide variety of people with HIV-1, including those simplifying from a three-drug regimen.

Rates of virologic failure were low in virologically suppressed individuals who switched to dolutegravir plus lamivudine, and rates of discontinuation due to adverse events were low and consistent with previously observed trial data.

Results from this systematic literature review demonstrate that real-world effectiveness and safety of dolutegravir plus lamivudine in clinical practice support data from randomized controlled trials regarding high rates of virologic response, low rates of discontinuation due to adverse events, and a high barrier to resistance.

\section{INTRODUCTION}

Recommended antiretroviral therapy (ART) regimens historically included a core agent such as a non-nucleoside reverse transcriptase inhibitor (NNRTI), boosted protease inhibitor (PI), or integrase strand transfer inhibitor (INSTI) plus 2 nucleoside reverse transcriptase inhibitors (NRTIs) [1]. These three-drug regimens (3DRs) have been successful at improving life expectancy for people with HIV (PWH) to near that of the general population [2]. Therefore, 
PWH are living longer and consequently will likely remain on ART for decades, in the continued absence of a cure. Antiretroviral therapy may contribute to comorbidities associated with aging, including renal, liver, or cardiovascular disease; osteoporosis; and metabolic disorders including diabetes and dyslipidemia [3-6]. Therefore, two-drug regimens (2DRs) have been investigated as a means of reducing the number of antiretroviral agents needed in a complete ART regimen. To be successful, a 2DR should include at least one antiretroviral agent with high potency and a high barrier to resistance [7]. Protease inhibitors were included in early investigations of 2DRs because of their high barrier to resistance and non-inferior efficacy to 3DRs [8-10]; however, long-term treatment with PIs is associated with cardiovascular and cerebrovascular disease as well as adverse metabolic effects including dyslipidemia and insulin resistance [11]. In addition, pharmacokinetic enhancements required with boosted PIs can lead to complex drug-drug interactions $[12,13]$; thus, the need for a well-tolerated, unboosted, potent 2DR with a high barrier to resistance remains.

The INSTI dolutegravir has a high barrier to resistance and has demonstrated high potency for inhibition of HIV-1 in phase III studies [14-16], making it well suited for use in a 2DR. Treatment with dolutegravir in combination with lamivudine in ART-naive participants through 144 weeks demonstrated long-term non-inferior efficacy vs. dolutegravir plus tenofovir disoproxil fumarate/emtricitabine in the phase III GEMINI-1 and -2 studies [17]. Treatment with dolutegravir plus lamivudine and dolutegravir plus tenofovir disoproxil fumarate/ emtricitabine led to similar rapid declines in plasma HIV-1 RNA regardless of baseline viral load, similar discontinuation rates, and few instances of participants meeting confirmed virologic withdrawal criteria and only one case of resistance in a participant with reported nonadherence on dolutegravir plus lamivudine [17-19]. Additionally, switching to the fixeddose combination dolutegravir/lamivudine in adults with HIV-1 suppressed on a three- or four-drug tenofovir alafenamide-based regimen demonstrated good safety with non-inferior efficacy compared with continuing on a tenofovir alafenamide-based regimen in the phase III TANGO study, with no confirmed virologic withdrawals or observed resistance through 144 weeks in the dolutegravir/lamivudine treatment group [20]. These data led to the marketing authorization (starting in 2019) of the fixed-dose combination of dolutegravir/ lamivudine as a once-daily, single-tablet 2DR by the US Food and Drug Administration (FDA) [21], European Medicines Agency [22], Australian Therapeutic Goods Administration [23], and Japanese Ministry of Health, Labour and Welfare [24]. In addition, dolutegravir/lamivudine is included as a recommended or preferred first-line regimen and a switch option for virologically suppressed $\mathrm{PWH}$ in major international guidelines $[1,25,26]$.

Overall, approximately 1100 participants received dolutegravir plus lamivudine in the phase III GEMINI-1 and -2 and TANGO clinical studies $[19,27]$. Real-world evidence can provide data in populations that may be underrepresented in clinical trials-including women, older $\mathrm{PWH}$, PWH from diverse racial backgrounds, and PWH with comorbiditiesand can aid understanding of the generalizability of the effectiveness and safety results from these clinical studies to a more diverse population as is treated in clinical practice. Published data from $\mathrm{PWH}$ using dolutegravir plus lamivudine in real-world settings are available, and there is accumulating evidence for the effectiveness of this 2DR in clinical practice. The objective of this systematic literature review was to identify and summarize realworld evidence in published literature from January 1, 2013, to December 31, 2020, regarding the effectiveness, safety, and barrier to resistance of dolutegravir plus lamivudine.

\section{METHODS}

\section{Search Strategy}

A systematic literature review of Ovid MEDLINE $^{\circledR}$, Embase $^{\circledR}$, PubMed, and Cochrane Central Register of Controlled Trials databases was conducted on December 31, 2020, to identify 
real-world observational studies of dolutegravir plus lamivudine in PWH. In addition, relevant conference proceedings (listed in Fig. 1) were manually searched. Key terms included in the search strings were related to HIV, study types typically associated with real-world evidence (Embase and MEDLINE searches only), and dolutegravir (full search strategies are reported in Table S1 in Supplementary Material).

\section{Eligibility Criteria}

Eligible studies were articles and conference presentations on the 2DR dolutegravir plus lamivudine (either dosed separately or as a fixed-dose combination) in PWH in non-interventional and observational studies. Eligibility assessment was independently reviewed by two reviewers. Any discrepancies between the decisions of the two reviewers at either stage of screening were resolved by a third independent reviewer. Titles and abstracts were screened during the initial stage, and then full-text articles were screened during the second stage. Only articles with publication dates from January 1, 2013, through December 31, 2020, were included; studies with $<10 \mathrm{PWH}$, case reports, reviews, and editorials were excluded as were preclinical, in vitro, animal, or controlled studies.

Linked publications were identified based on trial identifiers in addition to reporting of population, sites, and study period. Studies were also reviewed to assess whether there was potential duplication in reporting of outcomes for cohorts and populations. If duplication of cohort/population was suspected, the publication reporting the highest number of $\mathrm{PWH}$ receiving dolutegravir plus lamivudine, the overarching study, was included in the analysis.

\section{Data Extraction}

Data were extracted from eligible studies using a list of data outputs that was determined before the extraction. If more than one publication was identified as describing a single trial (linked publication), the data were compiled into a single entry in the data extraction table to avoid double counting PWH and studies. Information was extracted from each included study on (1) number of $\mathrm{PWH}$ receiving dolutegravir plus lamivudine; (2) prior ART experience; (3) previous treatment regimens and duration of ART; (4) baseline resistance; (5) baseline demographic characteristics; (6) effectiveness outcomes; (7) virologic failure; (8) treatment-emergent resistance; (9) treatment discontinuations; and (10) lipid, renal, and bone mineral density (BMD) outcomes. To determine the quality of eligible observational studies, a single reviewer assessed the extent of loss to follow-up as well as the methods of selecting $\mathrm{PWH}$, assessing effectiveness outcomes, and handling missing data using the Downs and Black checklist [28]. All information was extracted from the published material; there were no instances of personal communication with the author to confirm or retrieve data.

This article is based on previously conducted studies and does not contain any new studies with human participants or animals performed by any of the authors.

\section{RESULTS}

Of the 2657 records identified through database search using Ovid MEDLINE, Embase, PubMed, and Cochrane Library databases and conference information, 240 were removed as duplicates and 761 studies remained after the screen of the title and abstract and were further screened for the full-text article. Of these, 367 articles and 186 conference abstracts (reporting data on dolutegravir-based regimens) were screened for data evaluating dolutegravir dual therapy ( $n=141)$. Seventy-three of the 141 publications met the inclusion criteria for reporting data on dolutegravir plus lamivudine and included 34 cohorts not suspected to be linked or to include duplicate data (Fig. 1). Quality measures assessing the risk of bias within these studies are presented in Table S2 in Supplementary Material. 


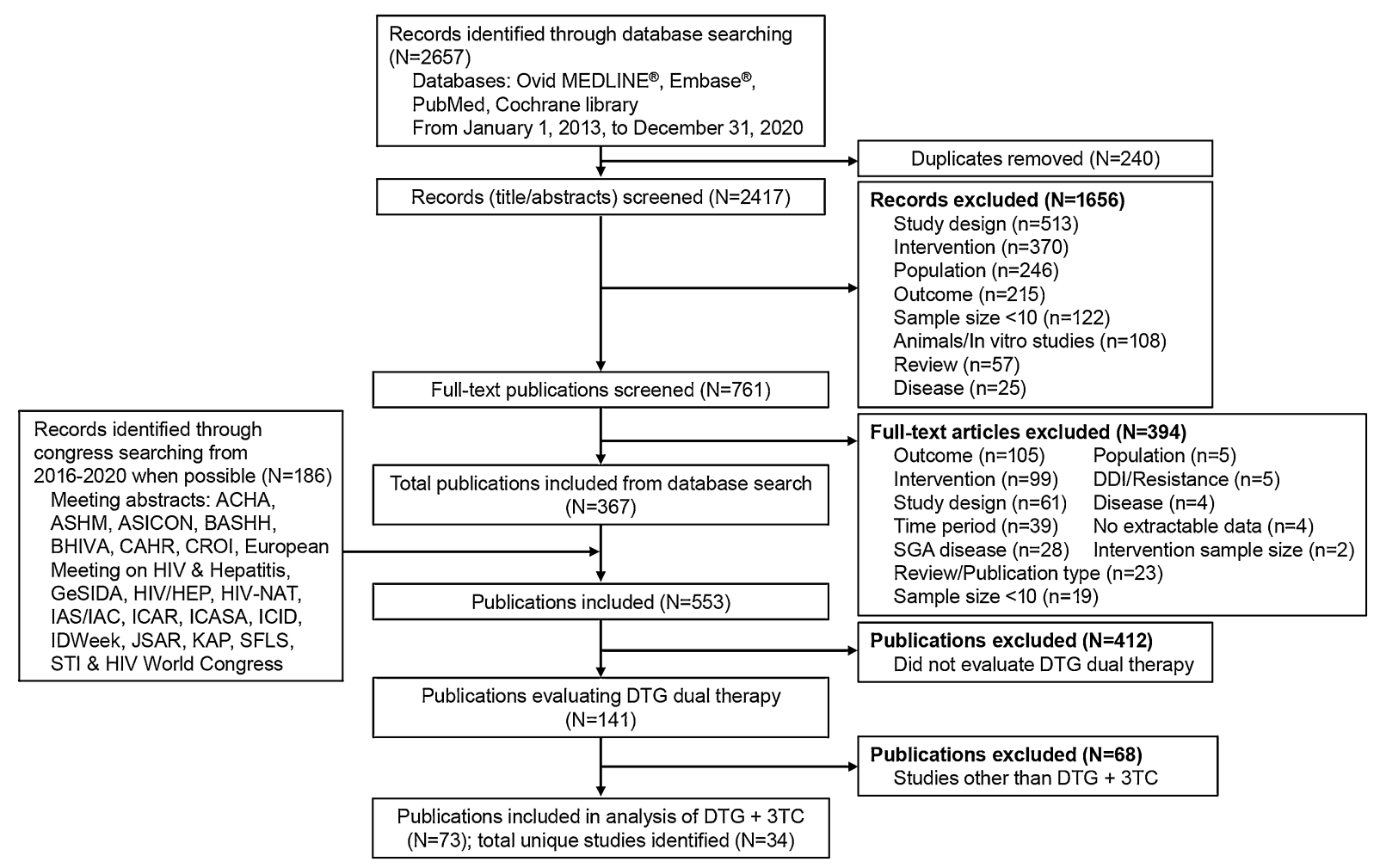

Fig. 1 Flow diagram of literature search for systematic review. ACHA Asian Conference on Hepatitis and AIDS, ASHM Australasian HIV \& AIDS Conference, ASICON National Conference of AIDS Society of India, $B A S H H$ British Association for Sexual Health and HIV, BHIVA British HIV Association, CAHR Canadian Conference on HIV/AIDS Research, CROI Conference on Retroviruses and Opportunistic Infections, DDI drug-drug interaction, $D T G$ dolutegravir, GeSIDA Grupo de Estudio del SIDASEIMC, HIV/HEP HIV \& Hepatitis in the Americas,

\section{Baseline Characteristics}

This analysis included $5017 \mathrm{PWH}$ who were reported to be using dolutegravir plus lamivudine. In 20 studies that reported data for sex, the majority of PWH treated with dolutegravir plus lamivudine were male (range, 60-97\%) [29-48]. In five of seven studies with reported racial demographics, $\geq 90 \%$ of $\mathrm{PWH}$ were identified as White [30, 32, 33, 42, 43, 46, 47]. In the other two studies, one population was 29\% White, 45\% Black, and 27\% Hispanic [42] and the other population was 52\% White, 35\% Black, and 13\% Asian [43]. Median ages ranged
HIV-NAT The HIV Netherlands Australia Thailand Research Collaboration, IAS/IAC International AIDS Society/International AIDS Conference, ICAR International Conference on Antiviral Research, ICASA International Conference on AIDS and STIs in Africa, ICID International Congress on Infectious Diseases, JSAR Japanese Society for AIDS Research, KAP Kenya Association of Physicians, SFLS Société Française De Lutte Contre Le Sida, $S G A$ small for gestational age, $S T I$ sexually transmitted infection, $3 T C$ lamivudine

from 34.0 to 60.5 years among the 17 studies that reported median age [29-37, 39, 41, 42, 44, 45, 47, 48]. Among studies clearly reporting treatment history, 4474 individuals switched from another regimen, and 73 were treatment naive (effectiveness was reported in 3489 and $69 \mathrm{PWH}$, respectively). Those who switched from another regimen had extensive ART experience ranging from 1.3 to 17.9 years in studies that reported prior ART duration [29, 30, 32-36, 38, 41, 42, 44, 46-49]. This analysis includes 1251 individuals who switched to dolutegravir plus lamivudine with no prior virologic failure and no known resistance where reported across eight studies 
$[29,34,43,47,50-53]$. Previous virologic failure was reported for $603 \mathrm{PWH}$ in 9 studies $[29,30,34,35,41,43,45,46,48]$. Baseline substitutions associated with ART resistance were reported in 286/1668 (17\%) PWH with available baseline genotype data [30, 31, 34, 35, 40, 45, 48, 54-56]. Among studies that reported information on prior regimens $(n=1958)$, many PWH switched to dolutegravir plus lamivudine from 3DRs ( $n=1718$; 88\%) [29, 35, 42, 43, 48, 49, 54, 57]. Primary reasons for switching to dolutegravir plus lamivudine included toxicity of the previous regimen $[48,52]$, avoidance of drug interactions [36, 48, 52, 53], treatment regimen simplification [34, 48, 52, 58], and comorbidities (including cardiovascular, renal, and bone disease) [34, 53, 58]. Of the comorbidities reported at baseline, bone, hypertension, liver, and metabolic comorbidities were most prevalent (Table 1) [32]. In 3 studies $(n=1028)$ that reported baseline prevalence of $\mathrm{PWH}$ with hepatitis B virus (HBV) coinfection who were treated with dolutegravir plus lamivudine, 19 were reported to have a positive hepatitis $B$ surface antigen test or chronic HBV infection at baseline $[29,34,40]$.

\section{Virologic Effectiveness of Dolutegravir Plus Lamivudine in Real-world Settings}

Four studies investigated the on-treatment effectiveness of dolutegravir plus lamivudine in 69 treatment-naive PWH (Table S3 in Supplementary Material) [31, 40, 43, 44]. In one study, after 4 weeks of dolutegravir plus lamivudine therapy, all $17 \mathrm{PWH}$ with available data had HIV-1 RNA $<200$ copies/ml [40]. At Week 8, two studies reported $89 \%(8 / 9)$ and $100 \%(4 / 4)$ of PWH with HIV-1 RNA $<50$ copies $/ \mathrm{ml}$, respectively [31, 43]. In the former study, all seven PWH with follow-up and five with 48 weeks of follow-up achieved HIV-1 RNA $<50$ copies/ml [31]. After 6 months, one study reported 90\% (19/21) of PWH achieving HIV-1 RNA $<50$ copies/ml; one (5\%) individual had HIV-1 RNA $\geq 200$ copies/ml, but none discontinued because of virologic failure [44]. One individual was reported to have baseline D232N
INSTI mutation and had undetectable viral load at last follow-up (8 weeks) [31].

The way that effectiveness outcomes in virologically suppressed PWH were assessed varied among studies included in this analysis. Outcomes included proportion of PWH achieving virologic suppression (plasma HIV-1 RNA $<50$ copies/ml) [32, 52], estimated probability of maintaining virologic suppression [30, 48, 59-61], and absence of virologic failure [62] or estimated probability of remaining free of virologic failure [63-65], defined as two consecutive viral loads $\geq 50$ copies $/ \mathrm{ml}$ or a single viral load $\geq 1000$ copies $/ \mathrm{ml}$. Virologic effectiveness observed across five cohorts with $\geq 100$ suppressed switch PWH $(\mathrm{n}=2224)$ ranged from $97 \%$ to $100 \%$ at Week 48 (Fig. 2) $[29,30,32,48,52]$ and $92 \%$ to $100 \%$ at Week 96 $[29,30,32,48]$; virologic failures per 100 person-years of follow-up (PYFU) ranged from 0 to 3.3 at Week 48 (Fig. 2).

In the only study that reported effectiveness data specifically in PWH with reported history of virologic failure regardless of the presence of M184I/V, detection of HIV-1 RNA $\geq 50$ copies/ $\mathrm{ml}$ occurred in 1.4-1.9 events per 100 PYFU in $194 \mathrm{PWH}$ with previous virologic failure and 0.5-1.0 events per 100 PYFU in $772 \mathrm{PWH}$ without previous virologic failure [29]. In several cohorts that included virologically suppressed PWH with historic M184I/V substitution $(n=154)$ before treatment switch to dolutegravir plus lamivudine, five PWH experienced virologic failure (3\%; Table 2$)$, and none of the five had treatment-emergent resistance-associated INSTI substitution at virologic failure [30, 33, 45, 48, 52, 55, 66].

\section{Treatment-Emergent Resistance}

Documented resistance-associated substitutions were detected in two individuals treated with dolutegravir plus lamivudine with accompanying baseline genotypic data among all studies in which effectiveness was evaluated and regardless of prior ART experience $(n=3558 ;<1 \%$; Fig. S1 in Supplementary Material) $[48,52]$. In one individual who was virologically suppressed at time of switch to dolutegravir plus 


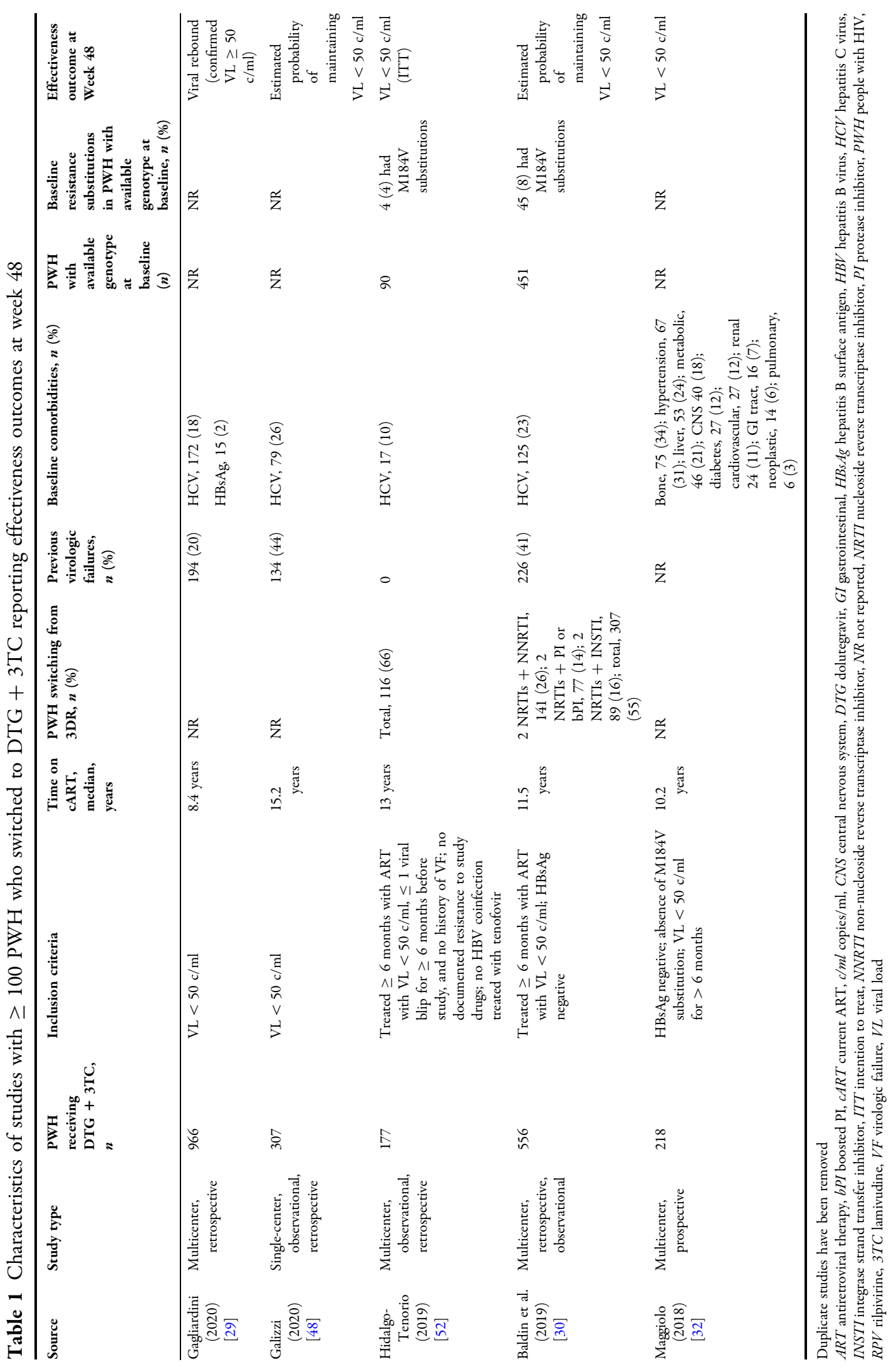


lamivudine and whose history of previous virologic failure was unreported, NRTI resistance-associated substitution $\mathrm{M} 41 \mathrm{M} / \mathrm{L}$ was detected at virologic failure but not before starting dolutegravir plus lamivudine. No INSTI substitutions were detected, and HIV-1 RNA levels were 65 and 107 copies/ml at virologic failure [48]. The other individual had a viral load of 229 copies/ml and no previous history of virologic failure or documented resistanceassociated mutations when switching from raltegravir plus abacavir/lamivudine to dolutegravir plus lamivudine. At virologic failure, the S147G integrase substitution was detected (HIV1 RNA 1123-8899 copies/ml), and virologic suppression was achieved after adding boosted darunavir to the existing dolutegravir plus lamivudine regimen (HIV-1 RNA 131 copies/ml) [52].

In a separate retrospective study analyzing ten PWH with no previous history of virologic failure who experienced virologic failure after dolutegravir plus lamivudine use, two had M184V/I at failure and one had E138A. However, there were no historic resistance data available to inform whether these were present before use of the 2DR [67].

\section{Rate of Discontinuations} with Dolutegravir Plus Lamivudine

In studies with available safety data regardless of ART experience, discontinuations occurred in $2-20 \%$ of the cohorts $[30,32,33,36,41,43,44,48,52,68]$, and in the five studies with available safety data and $\geq 100$ $\mathrm{PWH}$, discontinuations due to adverse events (AEs) or treatment intolerance/toxicity occurred in 2\% to 8\% (Fig. S2 in Supplementary Material) $[30,32,39,44,52]$. The most commonly reported reasons for discontinuation due to AEs/toxicity included neuropsychiatric, gastrointestinal and hepatic, and renal events. Neuropsychiatric AEs led to treatment discontinuations in $1 \%$ to $3 \%$ of $\mathrm{PWH}$ (Fig. S2 in Supplementary Material) [30, 32, 39, 52]. Neuropsychiatric outcomes resulting in discontinuation of dolutegravir plus lamivudine included insomnia, anxiety, headache, mood disorders, and sudden onset of nightmares [30, 32, 52]. Although no HBV flares were reported and a modest increase in liver enzymes occurred in one $\mathrm{PWH}$, that individual did not discontinue treatment [34].

\section{Renal Outcomes in PWH Receiving Dolutegravir Plus Lamivudine}

Six studies (all in virologically suppressed PWH) switching to dolutegravir plus lamivudine assessed serum creatinine levels and estimated glomerular filtration rate (eGFR) measured by creatinine clearance (Table 3) $[34,36,42,52,69,70]$. Although increases in serum creatinine $[52,69]$ and decreases in eGFR $[36,70]$ were reported, changes were minimal and generally not considered to be clinically significant.

\section{Lipid Outcomes in PWH Switching to Dolutegravir Plus Lamivudine}

Of five studies reporting lipid outcomes (all in virologically suppressed $\mathrm{PWH}$ ), two reported no statistically significant changes from baseline in lipid parameters $[34,36]$, and three reported significant improvements from baseline (Table 3). Overall, switching to dolutegravir plus lamivudine was associated with reductions in total cholesterol and triglycerides [30, 69]; increases in high-density lipoprotein cholesterol was observed in two of three studies [30, 52, 69]. Two studies reported that switching to dolutegravir plus lamivudine from a PI- or INSTI-based regimen was associated with more pronounced improvement in total cholesterol and/or triglycerides [30], whereas previous tenofovir disoproxil fumarate use was predictive of an increase in total cholesterol or triglyceride levels after switching to dolutegravir plus lamivudine $[60,64]$. However, other studies found that pre-switch regimens were not predictive of changes in lipid profiles after switching to dolutegravir plus lamivudine [52, 59]. 


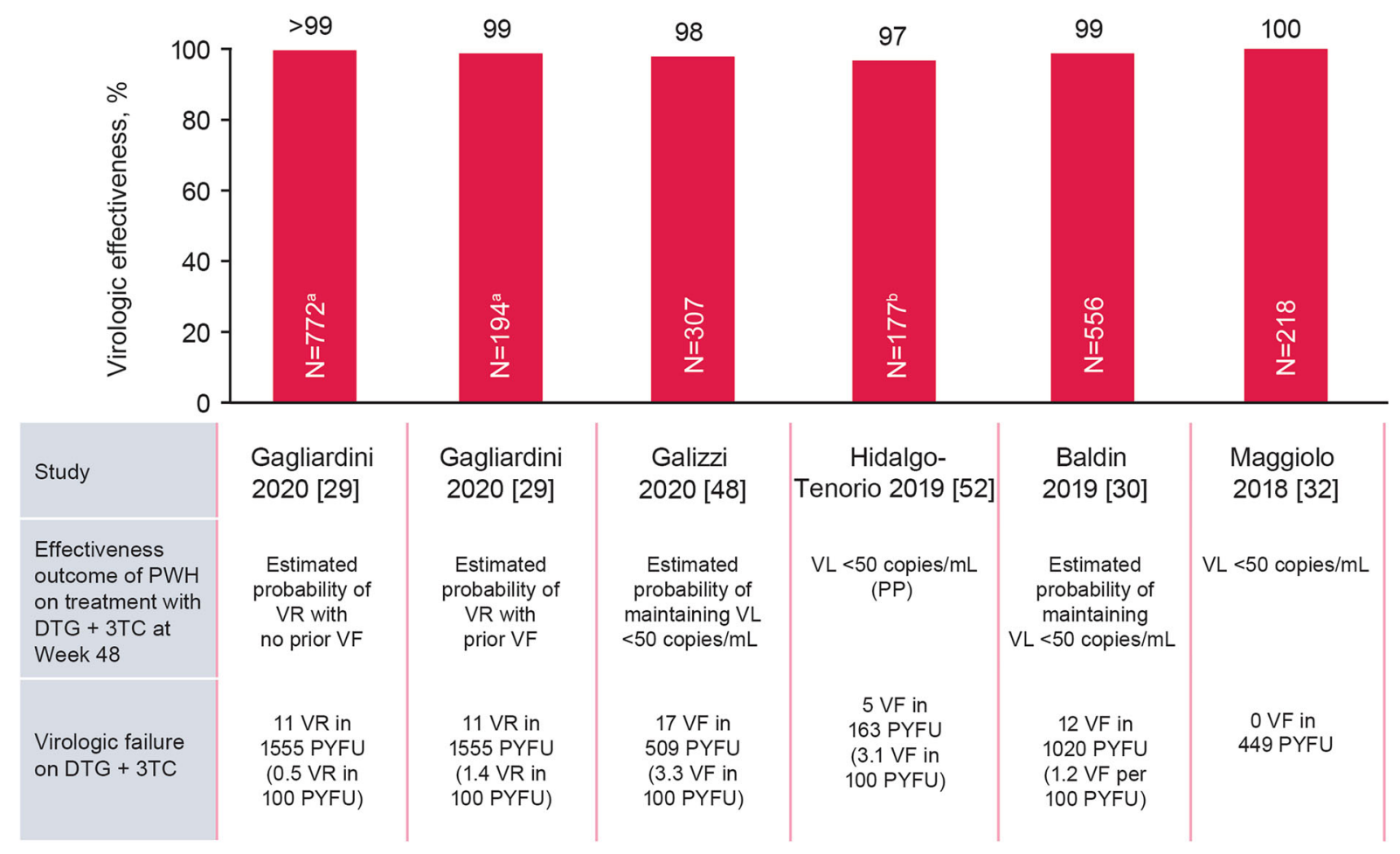

Fig. 2 Proportion of PWH in switch cohorts treated with DTG + 3TC reporting effectiveness at Week 48. Data included for studies with $\mathrm{N} \geq 100$. Duplicate studies have been removed. DTG dolutegravir, $P P$ per protocol, $P W H$ people with HIV, PYFU person-years of follow-up, 3TC

\section{Bone Health}

Three studies (all in virologically suppressed $\mathrm{PWH}$ ) examined the effect of dolutegravir plus lamivudine on BMD (Table S4 in Supplementary Material) [71-73]. Two of these studies reported significant improvements from baseline in spine BMD at Week 48 (mean increase from baseline in lumbar spine $\mathrm{BMD},+0.03 \mathrm{~g} /$ $\mathrm{cm}^{2} ; P=0.001$ ) [71] or Week 96 (percentage increase from baseline in spine BMD, 3.2; $P<0.001$ ) [72], and the third reported no difference compared with baseline [73]. One study found that length of exposure to tenofovir disoproxil fumarate in pre-switch regimens was a negative predictor of BMD improvement [71]. lamivudine, $V F$ virologic failure, $V L$ viral load, $V R$ virologic rebound. ${ }^{a} N=772 \mathrm{PWH}$ with no prior VF; $N=194 \mathrm{PWH}$ with $\geq 1$ prior VF. ${ }^{\mathrm{b}} N$ is for overall population and includes $6 \mathrm{PWH}$ who were not suppressed at baseline

\section{DISCUSSION}

In this systematic literature search of real-world studies, dolutegravir plus lamivudine has been observed to be prescribed for 5017 PWH with a wide spectrum of ART experience, including 603 who experienced previous virologic failure before switching to dolutegravir plus lamivudine. Overall, high rates of virologic suppression were maintained with dolutegravir plus lamivudine regardless of prior virologic failure, with high proportions of PWH achieving specified effectiveness outcomes at Weeks 48 and 96. In addition, rates of virologic failure were low in virologically suppressed PWH who switched to dolutegravir plus lamivudine, though history of previous virologic failure was associated with a modest increase in virologic failure, consistent with previous analyses showing that prior virologic failure is a significant risk factor 


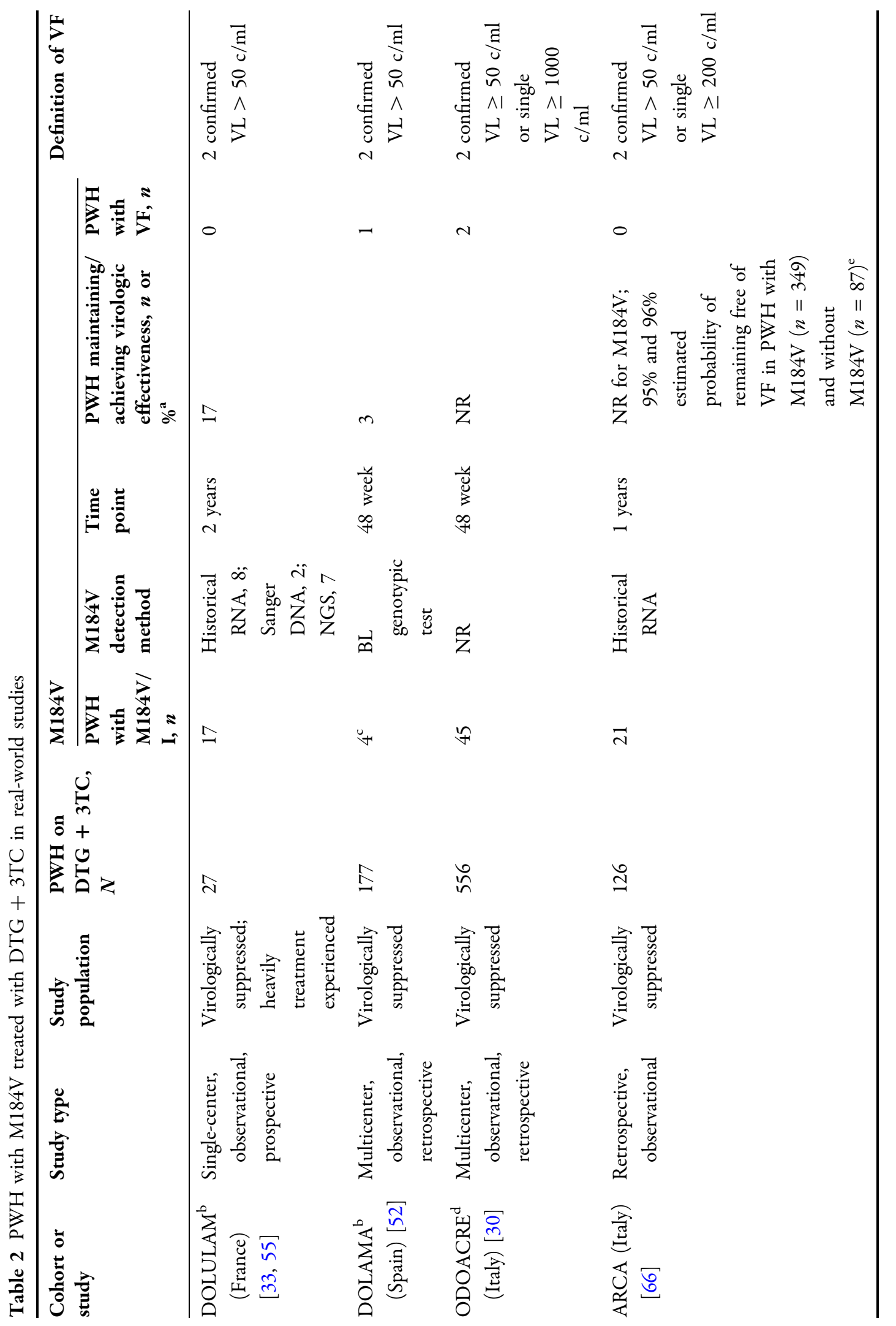




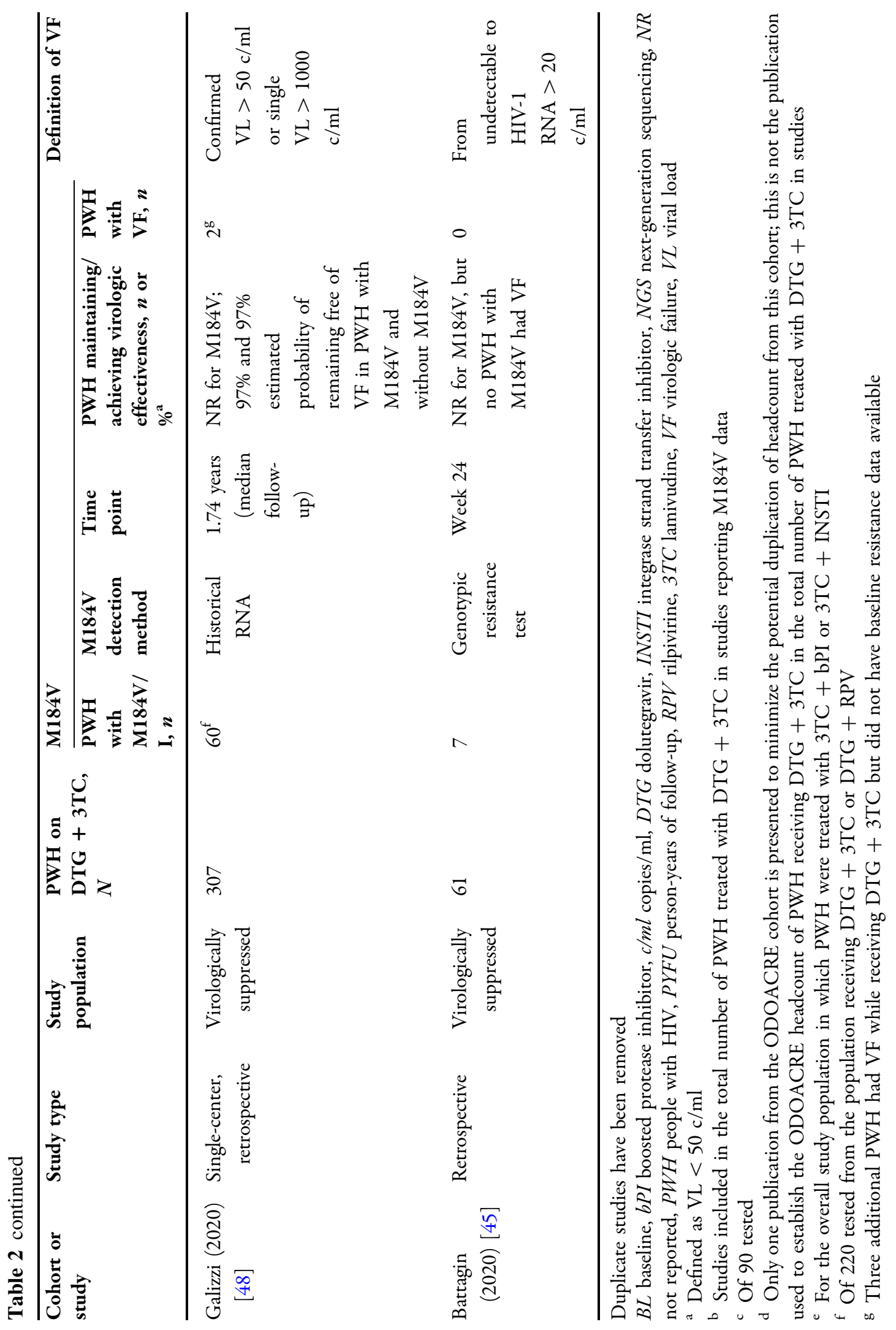


Table 3 Reported lipid and renal outcomes in PWH receiving DTG +3 TC

\begin{tabular}{|c|c|c|c|c|c|}
\hline Study & $\begin{array}{l}\text { PWH on } \\
\text { DTG + 3TC, } \\
N\end{array}$ & $\begin{array}{l}\text { Time } \\
\text { point } \\
(\text { week) }\end{array}$ & Lipid outcomes with DTG + & 3TC vs. BL & $\begin{array}{l}\text { Renal outcomes with } \\
\text { DTG + 3TC vs. BL }\end{array}$ \\
\hline $\begin{array}{l}\text { Maggiolo } \\
\qquad(2017) \\
{[69]}\end{array}$ & 94 & 24 & $\begin{array}{l}\text { Significant decrease in TC } \\
\qquad(-7 \mathrm{mg} / \mathrm{dl} ; P=0.047) \text { and } \\
\text { TG }(-31 \mathrm{mg} / \mathrm{dl} ; P=0.012) \\
\text { Significant increase in HDL } \\
\quad(+4 \mathrm{mg} / \mathrm{dl} ; P=0.036) \\
\text { No significant change in LDL } \\
(-7 \mathrm{mg} / \mathrm{dl} ; P=0.355)\end{array}$ & Improved & $\begin{array}{l}\text { Significant increase in mean } \\
\text { creatinine level was observed } \\
\text { in the first } 8 \text { weeks }(0.06 \mathrm{mg} / \\
\mathrm{dl} ; P<0.0001) \text { and leveled } \\
\text { out at } 24 \text { week }\end{array}$ \\
\hline $\begin{array}{l}\text { Hidalgo- } \\
\text { Tenorio } \\
(2019) \\
{[52]}\end{array}$ & 177 & 48 & $\begin{array}{l}\text { Significant decrease in TC } \\
\quad(-8 \mathrm{mg} / \mathrm{dl} ; P=0.002), \mathrm{TG} \\
(-48 \mathrm{mg} / \mathrm{dl} ; P=0.0001), \\
\text { and HDL }(-25 \mathrm{mg} / \mathrm{dl} ; \\
P=0.002) \\
\text { Significant increase in LDL } \\
(+14 \mathrm{mg} / \mathrm{dl} ; P=0.003) \text { and } \\
\text { TC:HDL ratio }(P=0.0018)\end{array}$ & Improved & $\begin{array}{l}\text { Significant increase in mean } \\
\text { creatinine level from baseline } \\
(1.04 \mathrm{mg} / \mathrm{dl}) \text { to Week } 48 \\
(1.15 \mathrm{mg} / \mathrm{dl} ; P=0.001) \text { but } \\
\text { changes were not considered } \\
\text { clinically relevant }\end{array}$ \\
\hline $\begin{array}{l}\text { Reynes } \\
\qquad(2016) \\
{[70]}\end{array}$ & 27 & 48 & NR & - & $\begin{array}{l}\text { Median decrease from baseline } \\
\text { of }-2.5 \text { and }-9 \mathrm{ml} / \mathrm{min} / \\
1.73 \mathrm{~m}^{2} \text { for } \mathrm{PWH} \text { switching } \\
\text { from a previous regimen with } \\
\text { or without TDF, respectively }\end{array}$ \\
\hline $\begin{array}{l}\text { Yagci- } \\
\text { Caglayik } \\
(2017) \\
{[34]}\end{array}$ & 32 & 30 & $\begin{array}{l}\text { No statistically significant } \\
\text { change in lipids }\end{array}$ & Unchanged & $\begin{array}{l}\text { eGFR increased to }>60 \mathrm{ml} / \\
\mathrm{min} / \mathrm{m}^{2} \text { in } 3 \text { of } 13 \mathrm{PWH} \text { with } \\
\mathrm{BL} \text { eGFR }<60 \mathrm{ml} / \mathrm{min} / \mathrm{m}^{2} \\
\text { Creatinine increased in } 1 \\
\text { individual }\end{array}$ \\
\hline $\begin{array}{l}\text { Baldin } \\
\qquad(2019) \\
{[30]}\end{array}$ & 556 & 144 & $\begin{array}{l}\text { Significant decrease in TC } \\
\qquad(-9.1 \mathrm{mg} / \mathrm{dl} ; P=0.007) \\
\text { and TG }(-2.7 \mathrm{mg} / \mathrm{dl} ; \\
P=0.009) \\
\text { Significant increase in HDL } \\
(+5.4 \mathrm{mg} / \mathrm{dl} ; P=0.036)\end{array}$ & Improved & NR \\
\hline $\begin{array}{c}\operatorname{Tan}(2019) \\
{[36]}\end{array}$ & 56 & 112 & $\begin{array}{l}\text { No significant change in } \\
\text { unfasted TC levels }\end{array}$ & Unchanged & $\begin{array}{l}\text { Small decrease in median eGFR } \\
\text { from baseline }(-1 \mathrm{ml} / \mathrm{min} / \\
\left.1.73 \mathrm{~m}^{2}\right)\end{array}$ \\
\hline
\end{tabular}


Table 3 continued

\begin{tabular}{|c|c|c|c|c|}
\hline Study & $\begin{array}{l}\text { PWH on } \\
\text { DTG }+3 T C, \\
N\end{array}$ & $\begin{array}{l}\text { Time } \\
\text { point } \\
(\text { week) }\end{array}$ & Lipid outcomes with DTG + 3TC vs. BL & $\begin{array}{l}\text { Renal outcomes with } \\
\text { DTG + 3TC vs. BL }\end{array}$ \\
\hline $\begin{array}{l}\text { Hiryak } \\
(2020) \\
{[42]}\end{array}$ & 49 & 16 & NR & $\begin{array}{l}\text { No change in median serum } \\
\text { creatinine }(-0.06 \mathrm{mg} / \mathrm{dl} \\
\text { (IQR, }-0.15,0.06)\end{array}$ \\
\hline
\end{tabular}

Duplicate studies have been removed

$B L$ baseline, $D T G$ dolutegravir, $e G F R$ estimated glomerular filtration rate, $H D L$ high-density lipoprotein, $L D L$ low-density lipoprotein, $N R$ not reported, $P W H$ people with HIV, $T C$ total cholesterol, $T G$ triglycerides, $3 T C$ lamivudine

${ }^{a}$ Value in this column refers to the time point at which the outcome was reported or median follow-up/length of treatment if no specific time point was provided by the authors

for future virologic failure [74]. Because different methods were used to assess effectiveness outcomes across individual studies in this analysis, the ability to assess outcomes with dolutegravir plus lamivudine across real-world cohorts was limited. However, when only studies with the effectiveness outcome at Week 48 of HIV-1 RNA $<50$ copies/ml were considered, virologic effectiveness ranged from $97 \%$ to $100 \%$ at Week 48 and $92 \%$ to $100 \%$ at Week 96; one study reported $97 \%$ at Week 144 . In studies that reported effectiveness in PWH with M184V at baseline $(n=154)$, five PWH $(3 \%)$ experienced virologic failure on treatment with dolutegravir plus lamivudine, and none of the five had detected treatment-emergent INSTI mutations. Thus, these findings provide evidence for very high effectiveness of dolutegravir plus lamivudine in clinical practice and are consistent with results seen in the phase III TANGO study in which $<1 \%$ of PWH had HIV1 RNA $\geq 50$ copies/ml (per FDA algorithm) and $86 \%$ maintained virologic suppression (defined as HIV-1 RNA < 50 copies/ml) at Week 144 after switching to dolutegravir/lamivudine from a tenofovir alafenamide-based three- or four-drug regimen [20]. The high effectiveness observed in real-world clinical practice provides reassurance in broad patient types beyond those included in phase III clinical trials.

Among those for whom genotypic resistance testing was performed at follow-up, two PWH across real-world studies of dolutegravir plus lamivudine were reported to have treatmentemergent resistance substitutions identified at time of virologic failure, one of which was an integrase substitution. Even among PWH on dolutegravir plus lamivudine who experienced virologic failure and underwent genotypic resistance testing, the incidence of treatmentemergent resistance was very low. The rare observation of treatment-emergent resistance in real-world cohorts is consistent with the high barrier to resistance of dolutegravir plus lamivudine observed in phase III randomized controlled trials. In GEMINI-1 and -2, there was only one case of emergent resistance in $>700$ treatment-naive participants treated with dolutegravir plus lamivudine (administered as separate tablets) over 3 years, and in TANGO (where participants received fixed-dose dolutegravir/lamivudine), there were no cases of virologic failure or resistance reported in $>300$ virologically suppressed participants through 144 weeks on dolutegravir/lamivudine $[17,20]$. In these studies, there were no obvious trends of an impact of $\mathrm{M} 184 \mathrm{~V}$ substitution at time of switch and virologic effectiveness of dolutegravir plus lamivudine, particularly in $\mathrm{PWH}$ with long durations of virologic suppression $[30,66]$. One potential explanation for the limited impact of M184V on efficacy of the lamivudine-containing regimen is its association with decreased viral fitness and lower replication capacity, which could reduce the likelihood of viral rebound over time $[75,76]$. 
Overall, dolutegravir plus lamivudine was generally well tolerated, and rates of discontinuation due to AEs, toxicities, and intolerance were $<8 \%$, with follow-up times ranging from approximately $0.5-3$ years. In the studies included in this analysis, rate of discontinuation due to neuropsychiatric events was low $(<4 \%)$ and consistent with the safety profile of dolutegravir plus lamivudine in clinical studies $[19,27]$.

Several switch studies of dolutegravir plus lamivudine included in this analysis reported increases in creatinine levels $[52,69]$ and decreases in calculated creatinine clearance $[36,60,70,77]$, consistent with the known, non-pathological inhibitory effect of dolutegravir on creatinine secretion [78]. This analysis showed that switching to dolutegravir plus lamivudine was generally associated with minimal impact or improvements in total cholesterol and triglycerides, consistent with outcomes reported in the phase III TANGO study [27, 79]. Although real-world studies reporting on BMD outcomes with dolutegravir plus lamivudine are limited, two studies reported improvements in BMD after switching to dolutegravir plus lamivudine [71, 72], including in PWH previously on tenofovir disoproxil fumarate-containing regimens, which have been shown to negatively affect BMD [80]. This is consistent with the pooled analysis of the phase III GEMINI-1 and -2 trials in treatmentnaive $\mathrm{PWH}$ in which changes from baseline in bone biomarkers at Week 144 favored dolutegravir plus lamivudine compared with dolutegravir plus tenofovir disoproxil fumarate/ emtricitabine [17]. It should be noted that, unlike tenofovir disoproxil fumarate, the longterm effects of tenofovir alafenamide on bone and renal biomarkers and BMD is inconclusive. Taken together, a treatment regimen containing dolutegravir, which does not contain tenofovir and has a low risk of drug-drug interactions [81], may be an alternative treatment option for PWH with or at risk of renal, cardiovascular, or bone comorbidities, which is especially important as more $\mathrm{PWH}$ are aging and becoming increasingly at risk of these comorbidities.
Our systematic literature review has several limitations. Selection of studies was limited to those for which the authors chose to publish the research or present it at various HIV conferences. None of the studies that were retrospective analyses described how missing data were handled or reported data on adherence to medication, which could impact the observed treatment effect, for example, by underestimating tolerability issues not leading to treatment discontinuation. Although reporting of baseline regimens before switch was incomplete in the studies included in this analysis, based on the publication dates of some studies, it can be assumed that many individuals were switched from older regimens, which should be considered when assessing the overall efficacy and safety of dolutegravir plus lamivudine. Genotypic resistance testing was not performed in every individual with virologic failure, preventing a complete characterization of all virologic failures. In addition, although studies of duplicate populations were removed when identified, potential overlap between cohorts cannot be ruled out. Although the GEMINI-1 and -2 studies demonstrated efficacy and safety of dolutegravir plus lamivudine in ART-naive participants [19], only 1\% (73/5017) of PWH receiving dolutegravir plus lamivudine in realworld cohorts were ART naive at baseline, highlighting the need for additional data from this population. However, the effectiveness data observed for first-line use of dolutegravir plus lamivudine in ART-naive PWH $(n=69)$ resemble the results observed in clinical trials. Moreover, study populations were predominantly White (29-100\%) and male (60-97\%), and only one study reported effectiveness by baseline CD4 + cell count, highlighting the need for additional real-world effectiveness and safety data for dolutegravir plus lamivudine in other populations [31]. Dolutegravir plus lamivudine has the potential to be beneficial in an aging population with other comorbidities and polypharmacy, although more real-world data will be needed to understand the extent of the benefit associated with this 2DR in older populations. 


\section{CONCLUSION}

Dolutegravir plus lamivudine is a complete 2DR for the treatment of HIV-1 infection and reduces the number of antiretroviral drugs taken by individuals without compromising virologic control. On the basis of data reported from clinical practice, virologic suppression was achieved and maintained with dolutegravir plus lamivudine in a wide variety of $\mathrm{PWH}$, including those simplifying their treatment from a 3DR to a 2DR. The regimen is generally well tolerated, with little impact on existing comorbidities and a low rate of discontinuations due to AEs. Overall, results from this systematic literature review demonstrate that real-world effectiveness and safety of dolutegravir plus lamivudine in clinical practice support data from randomized controlled trials with regard to high rates of virologic response, low rates of discontinuation due to AEs, and a high barrier to resistance.

\section{ACKNOWLEDGEMENTS}

Funding. This research and the journal's Rapid Service Fee were funded by ViiV Healthcare. ViiV Healthcare played a role in the study design, data collection and analysis, and preparation of the manuscript. The corresponding author had full access to all study data and had final responsibility for the decision to submit for publication.

Medical Writing and/or Editorial Assistance. Editorial assistance was provided under the direction of the authors by Jeffrey Stumpf, $\mathrm{PhD}, \mathrm{CMPP}$, and Jennifer Rossi, MA, ELS, MedThink SciCom, and was funded by ViiV Healthcare.

Authorship. All named authors meet the International Committee of Medical Journal Editors (ICMJE) criteria for authorship for this article, take responsibility for the integrity of the work as a whole, and have given their approval for this version to be published.
Author Contributions. RP, LE, TV, JvW, and $\mathrm{JK}$ contributed to the conception and design of the research. DJ, RK, and RDK contributed to the acquisition and analysis of data. RP, LE, IM, $\mathrm{TV}$, JvW, and JK contributed to the interpretation of data. All authors contributed to critically revising the manuscript for important intellectual content and approved the manuscript for publication.

Prior Presentation. The systematic literature review methods have previously been presented in part at the 23rd International AIDS Conference; July 6-10, 2020; Virtual; Poster PDB0103.

Disclosures. RP, LE, IM, TV, JvW, and JK are employees of ViiV Healthcare and hold stock in GlaxoSmithKline. SDG has served as a paid consultant or member of advisory boards for Gilead, ViiV Healthcare, Janssen-Cilag, Merck Sharp \& Dohme, and Bristol-Myers Squibb. ADM is a professor at the University of Milan. JC has nothing to disclose. AC-U has received grants and personal fees from ViiV Healthcare, Gilead, Janssen, and Merck, outside the submitted work. LH has received personal fees and non-financial support from Gilead, Janssen, Merck Sharp \& Dohme, and ViiV Healthcare, outside the submitted work. CA has received honoraria or travel/meeting grants from Gilead, Merck Sharp \& Dohme, Janssen, and ViiV Healthcare, outside the submitted work. TB has received speaker fees, advisory board honoraria, and conference support from Roche, Thera, Janssen, Gilead, and ViiV Healthcare and currently holds education and research grants from Roche, Gilead, and ViiV Healthcare. DJ and RDK are employees of the GlaxoSmithKline Knowledge Centre. RK was an employee of the GlaxoSmithKline Knowledge Centre during this research and is now an employee of BITS Pilani, Pilani, Rajasthan.

Compliance with Ethics Guidelines. This article is based on previously conducted studies and does not contain any new studies with human participants or animals performed by any of the authors. 
Open Access. This article is licensed under a Creative Commons Attribution-NonCommercial 4.0 International License, which permits any non-commercial use, sharing, adaptation, distribution and reproduction in any medium or format, as long as you give appropriate credit to the original author(s) and the source, provide a link to the Creative Commons licence, and indicate if changes were made. The images or other third party material in this article are included in the article's Creative Commons licence, unless indicated otherwise in a credit line to the material. If material is not included in the article's Creative Commons licence and your intended use is not permitted by statutory regulation or exceeds the permitted use, you will need to obtain permission directly from the copyright holder. To view a copy of this licence, visit http://creativecommons.org/licenses/by$\mathrm{nc} / 4.0 /$.

\section{REFERENCES}

1. Panel on Antiretroviral Guidelines for Adults and Adolescents. Guidelines for the use of antiretroviral agents in adults and adolescents with HIV. Department of Health and Human Services (DHHS). 2019 https:/clinicalinfo.hiv.gov/sites/default/files/ guidelines/documents/AdultandAdolescentGL.pdf. Accessed 22 Mar 2021.

2. Trickey A, May MT, Vehreschild J-J, et al. Survival of HIV-positive patients starting antiretroviral therapy between 1996 and 2013: a collaborative analysis of cohort studies. Lancet HIV. 2017;4:e349-56.

3. Salter ML, Lau B, Go VF, Mehta SH, Kirk GD. HIV infection, immune suppression, and uncontrolled viremia are associated with increased multimorbidity among aging injection drug users. Clin Infect Dis. 2011;53:1256-64.

4. da Cunha J, Ferreira Maselli LM, Bassi Stern AC, Spada C, Bydlowski SP. Impact of antiretroviral therapy on lipid metabolism of human immunodeficiency virus-infected patients: old and new drugs. World J Virol. 2015;4:56-77.

5. Kumar S, Samaras K. The impact of weight gain during HIV treatment on risk of pre-diabetes, diabetes mellitus, cardiovascular disease, and mortality. Front Endocrinol (Lausanne). 2018;9:705.
6. Ofotokun I, Weitzmann MN. HIV and bone metabolism. Discov Med. 2011;11:385-93.

7. Back D. 2-Drug regimens in HIV treatment: pharmacological considerations. Germs. 2017;7:113-4.

8. Arribas JR, Girard P-M, Landman R, et al. Dual treatment with lopinavir-ritonavir plus lamivudine versus triple treatment with lopinavir-ritonavir plus lamivudine or emtricitabine and a second nucleos(t)ide reverse transcriptase inhibitor for maintenance of HIV-1 viral suppression (OLE): a randomised, open-label, non-inferiority trial. Lancet Infect Dis. 2015;15:785-92.

9. Cahn P, Andrade-Villanueva J, Arribas JR, et al. Dual therapy with lopinavir and ritonavir plus lamivudine versus triple therapy with lopinavir and ritonavir plus two nucleoside reverse transcriptase inhibitors in antiretroviral-therapy-naive adults with HIV-1 infection: 48 week results of the randomised, open label, non-inferiority GARDEL trial. Lancet Infect Dis. 2014;14:572-80.

10. Di Giambenedetto S, Fabbiani M, Quiros Roldan E, et al. Treatment simplification to atazanavir/ritonavir + lamivudine versus maintenance of atazanavir/ritonavir + two NRTIs in virologically suppressed HIV-1-infected patients: 48 week results from a randomized trial (ATLAS-M). J Antimicrob Chemother. 2017;72:1163-71.

11. Lv Z, Chu Y, Wang Y. HIV protease inhibitors: a review of molecular selectivity and toxicity. HIV AIDS (Auckl). 2015;7:95-104.

12. Prezista [package insert]. Beerse, Belgium: Janssen Pharmaceutica NV; 2021.

13. Kaletra [package insert]. North Chicago, IL: AbbVie; 2020.

14. Cahn P, Pozniak AL, Mingrone H, et al. Dolutegravir versus raltegravir in antiretroviral-experienced, integrase-inhibitor-naive adults with HIV: week 48 results from the randomised, double-blind, non-inferiority SAILING study. Lancet. 2013;382: 700-8.

15. Raffi F, Rachlis A, Stellbrink H-J, et al. Once-daily dolutegravir versus raltegravir in antiretroviralnaive adults with HIV-1 infection: 48 week results from the randomised, double-blind, non-inferiority SPRING-2 study. Lancet. 2013;381:735-43.

16. Brenner BG, Wainberg MA. Clinical benefit of dolutegravir in HIV-1 management related to the high genetic barrier to drug resistance. Virus Res. 2017;239:1-9.

17. Cahn P, Sierra Madero J, Arribas JR, et al. Durable efficacy of dolutegravir (DTG) plus lamivudine 
(3TC) in antiretroviral treatment-naive adults with HIV-1 infection-3-year results from the GEMINI studies. In: Paper presented at: HIV Drug Therapy Glasgow 2020; 2020 October 5-8; Virtual.

18. Cahn P, Sierra Madero J, Arribas JR, et al. Dolutegravir plus lamivudine versus dolutegravir plus tenofovir disoproxil fumarate and emtricitabine in antiretroviral-naive adults with HIV-1 infection (GEMINI-1 and GEMINI-2): week 48 results from two multicentre, double-blind, randomised, noninferiority, phase 3 trials. Lancet. 2019;393:143-55.

19. Cahn P, Sierra Madero J, Arribas JR, et al. Durable efficacy of dolutegravir plus lamivudine in antiretroviral treatment-naive adults with HIV-1 infection: 96-week results from the GEMINI-1 and GEMINI-2 randomized clinical trials. J Acquir Immune Defic Syndr. 2020;83:310-8.

20. van Wyk J, Ait-Khaled M, Santos J, Scholten S, et al. Metabolic health outcomes at Week 144 in the TANGO study, comparing a switch to DTG/3TC versus maintenance of TAF-based regimens. In: Paper presented at: 11th IAS Conference on HIV Science; 2021 July 18-21; Virtual.

21. Dovato [package insert]. Research Triangle Park, NC: ViiV Healthcare; 2021.

22. Dovato [summary of product characteristics]. ViiV Healthcare BV; 2020.

23. Dovato [Australian product information]. Abbotsford, Australia: ViiV Healthcare Pty Ltd; 2020.

24. Dovato combination tablets [pharmaceuticals and medical devices safety information]. Tokyo, Japan: ViiV Healthcare K.K; 2020.

25. European AIDS Clinical Society. Guidelines version 10.1. European AIDS Clinical Society (EACS). October 2020 https://www.eacsociety.org/files/ guidelines-10.1_finaljan2021_1.pdf. Accessed 22 Mar 2021.

26. Saag MS, Gandhi RT, Hoy JF, et al. Antiretroviral drugs for treatment and prevention of HIV infection in adults: 2020 recommendations of the International Antiviral Society-USA Panel. JAMA. 2020;324:1651-69.

27. van Wyk J, Ajana F, Bisshop F, et al. Efficacy and safety of switching to dolutegravir/lamivudine fixed-dose 2-drug regimen vs continuing a tenofovir alafenamide-based 3- or 4-drug regimen for maintenance of virologic suppression in adults living with human immunodeficiency virus type 1 : phase 3, randomized, noninferiority TANGO study. Clin Infect Dis. 2020;71:1920-9.
28. Downs SH, Black N. The feasibility of creating a checklist for the assessment of the methodological quality both of randomised and non-randomised studies of health care interventions. J Epidemiol Community Health. 1998;52:377-84.

29. Gagliardini R, Lorenzini P, Cozzi-Lepri A, et al. Effect of past virological failure on dolutegravir + lamivudine as maintenance regimen. In: Paper presented at: Conference on retroviruses and opportunistic infections; 2020 March 8-11; Boston, MA.

30. Baldin G, Ciccullo A, Rusconi S, et al. Long-term data on the efficacy and tolerability of lamivudine plus dolutegravir as a switch strategy in a multicentre cohort of HIV-1-infected, virologically suppressed patients. Int J Antimicrob Agents. 2019;54: 728-34.

31. Ciccullo A, Baldin G, Cossu MV, et al. Dolutegravir plus lamivudine as first-line regimen in a multicenter cohort of HIV-1-infected patients: preliminary data from clinical practice. AIDS Res Hum Retroviruses. 2020;36:4-5.

32. Maggiolo F, Comi L, Gulminetti R, et al. Dolutegravir + lamivudine in patients with suppressed HIV-RNA: long term virologic and immunologic results of a multicenter cohort. In: Paper presented at: HIV Drug Therapy Glasgow 2018; 2018 October 28-31; Glasgow, UK.

33. Charpentier C, Montes B, Perrier M, Meftah N, Reynes J. HIV-1 DNA ultra-deep sequencing analysis at initiation of the dual therapy dolutegravir + lamivudine in the maintenance DOLULAM pilot study. J Antimicrob Chemother. 2017;72:2831-6.

34. Yagci-Caglayik D, Gokengin D, Inan A, et al. Real life experience of dolutegravir and lamivudine dual therapy as a switching regimen in HIVTR cohort. In: Paper presented at: 16th European AIDS Conference; 2017 October 25-27; Milan, Italy.

35. Hidalgo-Tenorio C, de Jesús SE, Santos J, et al. DOLAM study: effectiveness and safety of a dual therapy with dolutegravir plus lamivudine in treatment-experienced HIV patients. In: Paper presented at: HIV Drug Therapy Glasgow 2018; 2018 October 28-31; Glasgow, UK.

36. Tan M, Johnston S, Nicholls J, Gompels M. Dual therapy with renally adjusted lamivudine and dolutegravir: a switch strategy to manage comorbidity and toxicity in older, suppressed patients? HIV Med. 2019;20:634-7.

37. Jarrin I, Moreno C, Suárez-García I, et al. Switching to dual therapies in treatment-experienced adults in a cohort of HIV-positive subjects (CoRIS), 
2014-2017 [P-162]. In: Presented at: X Congreso Nacional GeSIDA; 2018; Madrid.

38. Ferrer Ribera A, Oltra Sempere MR, Pinto Pla C, et al. Experience in clinical practice with regimes of 2 drugs based on dolutegravir. In: Paper presented at: X Congreso Nacional GeSIDA; 2018 November 6-9; Madrid, Spain.

39. Bravo J, Martinez O, Martinez-Alfaro E, et al. Multicenter study to evaluate the effectiveness and safety of dolutegravir and lamivudine dual therapy in real life. In: Paper presented at: XI Congreso Nacional GeSIDA; 2019 December 10-13; Toledo, Spain.

40. Cabello Úbeda A, Álvarez B, Prieto-Pérez L, et al. Experience of bytherapy with dolutegravir (DTG) + lamivudine (3TC) in naive patients outside the clinical trials. In: Paper presented at: XI Congreso Nacional GeSIDA; 2019 December 10-13; Toledo, Spain.

41. Uriel AJ, Banks T, Ashton K, Ustianowski A. Dual antiretroviral (ARV) therapy: safe and efficacious even in a heavily ARV experienced real-world cohort. In: Presented at: 26th Annual Conference of the British HIV Association; 2020 November 22-24; Virtual.

42. Hiryak K, Kludjian G, Samuel R, Bettiker R, Koren DE. Real-world implementation of dolutegravirlamivudine to achieve and maintain HIV-1 viral suppression at an academic medical center. In: Paper presented at: IDWeek 2020; 2020 October 21-25; Virtual.

43. Stephenson I, Pan D. Clinical experience of dolutegravir + lamivudine dual treatment regimens at University Hospitals of Leicester NHS Trust. In: Paper presented at: 26th Annual Conference of the British HIV Association; 2020 November 22-24; Virtual.

44. Postel N, Schneeweiss S, Wyen C. et al. Real-world data from the prospective URBAN cohort study on the use of dolutegravir (DTG) + lamivudine (3TC) in ART-naïve and pre-treated people living with HIV in Germany. In: Paper presented at: HIV Drug Therapy Glasgow 2020; 2020 October 5-8; Virtual.

45. Battagin G, Parisi S, Giordani M, et al. Dual HIV treatment in experienced HIV patients. In: Paper presented at: HIV Drug Therapy Glasgow 2020; 2020 October 5-8; Virtual.

46. Taramasso L, Bonfanti P, Ricci E, et al. Factors associated with weight gain in people treated with dolutegravir. Open Forum Infect Dis. 2020;7: ofaa195.
47. Calza L, Colangeli V, Borderi M, et al. Simplification to dual therapy containing lamivudine and raltegravir or dolutegravir in HIV-infected patients on virologically suppressive antiretroviral therapy. J Antimicrob Chemother. 2020;75:3327-33.

48. Galizzi N, Poli A, Galli L, et al. Retrospective study on the outcome of two-drug regimens based on dolutegravir plus one reverse transcriptase inhibitor in virologically-suppressed HIV-infected patients. Int J Antimicrob Agents. 2020;55:105893.

49. Cucchetto G, Lanzafame M, Nicolé S, et al. Integrase inhibitors with lamivudine, as maintenancedual therapy, in a real-life clinical setting. Paper presented at: Italian Conference on AIDS and Retroviruses; 2016 June 6-8; Milan, Italy.

50. Alves Correia RM, Camara Carvalho A. Real life study with dual therapy in a HIV-1 treatment experienced Portuguese cohort. In: Paper presented at: 23rd International AIDS Conference; 2020 July 6-10; Virtual.

51. Castelli A, Manzardo C, Ambrosioni J, et al. Simplification to dual (2D) antiretroviral therapy with lamivudine and dolutegravirin HIV-infected patients with solid organ transplantation: a preliminary single-center experience. In: Paper presented at: 17th European AIDS Conference; 2019 November 6-9; Basel, Switzerland.

52. Hidalgo-Tenorio C, López Cortés L, Gutiérrez A, et al. DOLAMA study: effectiveness, safety and pharmacoeconomic analysis of dual therapy with dolutegravir and lamivudine in virologically suppressed HIV-1 patients. Medicine (Baltimore). 2019;98:e16813.

53. Tan M, Johnston S, Nicholls J, Gompels M. Dual therapy with dolutegravir and renally adjusted lamivudine in HIV infection: a treatment strategy to manage comorbidity and toxicity in older patients. HIV Med. 2018;19(suppl 2):s24.

54. Gagliardini R, Rossetti B, Redi D, et al. Impact of resistance mutations on virological efficacy of DTGbased maintenance two-drug regimens: an ARCA cohort study. In: Paper presented at: 11th Italian Conference on AIDS and antiviral research; 2019 June 6-8; Milan, Italy.

55. Reynes J, Meftah N, Tuaillon E, Charpentier C, Montes B. Dual regimen with dolutegravir and lamivudine maintains virologic suppression even in heavily treatment experienced HIV-infected patients: 96 weeks results from maintenance DOLULAM study. In: Paper presented at: 9th IAS Conference on HIV Science; 2017 July 23-26; Paris, France. 
56. Hart J, Burns F, Katiyar A, Youle M, Barber T. Experience of dolutegravir/lamivudine (DTG/3TC) and dolutegravir/rilpivirine (DTG/RPV) two drug anti-retroviral regimens in a London tertiary centre. In: Paper presented at: 25th Annual Conference of the British HIV Association; 2019 April 2-5; Bournemouth, UK.

57. Belmonti S, Lombardi F, Cingolani A, et al. Switch to dolutegravir-based regimens and decrease in sCD14 levels in HIV-1 infected patients on suppressive ART. In: Paper presented at: 11th Italian Conference on AIDS and antiviral research; 2019 June 6-8; Milan, Italy.

58. Pereira Goulart S, de Alburquerque Moraes C, Furtado da Costa Á, et al. ART simplification: use of dual therapy for HIV in a public health reference center (CRT-DST/Aids) in São Paulo, Brazil. In: Paper presented at: 17th European AIDS Conference; 2019 November 6-9; Basel, Switzerland.

59. Borghetti A, Baldin G, Lombardi F, et al. Efficacy and tolerability of lamivudine plus dolutegravir as a switch strategy in a multicentre cohort of patients with suppressed HIV-1 replication. HIV Med. 2018;19:452-4.

60. Ciccullo A, Baldin G, Capetti A, et al. A comparison between two dolutegravir-based two-drug regimens as switch strategies in a multicentre cohort of HIV1-infected patients. Antivir Ther. 2019;24:63-7.

61. Baldin G, Borghetti A, Ciccullo A, et al. Shall we dance? Extending TANGO's results to clinical practice. In: Paper presented at: Conference on retroviruses and opportunistic infections; 2020 March 8-11; Boston, MA.

62. Joly V, Burdet C, Landman R, for the LAMIDOL Study Group, et al. Dolutegravir and lamivudine maintenance therapy in HIV-1 virologically suppressed patients: results of the ANRS 167 trial (LAMIDOL). J Antimicrob Chemother. 2019;74: 739-45.

63. Baldin G, Ciccullo A, Borghetti A, Di Giambenedetto S. Virological efficacy of dual therapy with lamivudine and dolutegravir in HIV-1-infected virologically suppressed patients: long-term data from clinical practice. J Antimicrob Chemother. 2019;74:1461-3.

64. Borghetti A, Lombardi F, Gagliardini R, et al. Efficacy and tolerability of lamivudine plus dolutegravir compared with lamivudine plus boosted PIs in HIV-1 positive individuals with virologic suppression: a retrospective study from the clinical practice. BMC Infect Dis. 2019;19:59.

65. Fabbiani M, Rossetti B, Ciccullo A, et al. Efficacy and durability of 2-drug vs 3-drug INSTI-based regimens: data from real-life. In: Paper presented at: Conference on retroviruses and opportunistic infections; 2020 March 8-11; Boston, MA.

66. Gagliardini R, Ciccullo A, Borghetti A, et al. Impact of the M184V resistance mutation on virological efficacy and durability of lamivudine-based dual antiretroviral regimens as maintenance therapy in individuals with suppressed HIV-1 RNA: a cohort study. Open Forum Infect Dis. 2018;5:ofy113.

67. Calvez V, Armenia D, Charpentier C, et al. Clinical consequences of failing PI and DTG-based two drug combinations versus PI and INI based triple therapies in HIV patients without previous virological failures. In: Paper presented at: HIV Drug Therapy Glasgow 2018; 2018 October 5-8; Glasgow, UK.

68. Micheli V, Rizzelli D, Mileto D, et al. Durability and efficacy of dolutegravir-based 2 drug regimens in virologically suppressed patients: a real life clinical setting. In: Paper presented at: 11th Italian Conference on AIDS and Antiviral Research; 2019 June 6-8; Milan, Italy.

69. Maggiolo F, Gulminetti R, Pagnucco L, et al. Lamivudine/dolutegravir dual therapy in HIV-infected, virologically suppressed patients. BMC Infect Dis. 2017;17:215.

70. Reynes J, Meftah N, Montes B. Dual regimen with dolutegravir and lamivudine maintains virologic suppression even in heavily treatment experienced HIV-infected patients: 48 weeks results from a pilot study (DOLULAM). In: Paper presented at: HIV Drug Therapy Glasgow 2016; 2016 October 23-26; Glasgow, UK.

71. Ciccullo A, D'Avino A, Lassandro AP, et al. Changes in bone mineral density in HIV-positive, virologically suppressed patients switching to lamivudine/dolutegravir dual therapy: preliminary results from clinical practice. Infez Med. 2018;26: 336-40.

72. Piscaglia M, Gallazzi I, Restelli S, et al. Impact on bone mineral density after two years of switching to four dolutegravir-based triple or dual regimens. In: Paper presented at: HIV Drug Therapy Glasgow 2018; 2018 October 28-31; Glasgow, UK.

73. Calza L, Borderi M, Colangeli V, et al. No significant changes in weight and body fat mass in suppressed HIV-infected patients switched to dual combination lamivudine plus dolutegravir or raltegravir. AIDS Res Hum Retrovir. 2021;37:204-6.

74. Robbins GK, Johnson KL, Chang Y, et al. Predicting virologic failure in an HIV clinic. Clin Infect Dis. 2010;50:779-86. 
75. Miller V, Stark T, Loeliger AE, Lange JMA. The impact of the M184V substitution in HIV-1 reverse transcriptase treatment. HIV Med. 2002;3:135-45.

76. Kumar PN, Patel P. Lamivudine for the treatment of HIV. Expert Opin Drug Metab Toxicol. 2010;6: 105-14.

77. Baldin G, Ciccullo A, Rusconi S, et al. Single tablet regimen with abacavir/lamivudine/dolutegravir compared with two-drug regimen with lamivudine and dolutegravir as different strategies of simplification from a multicenter HIV cohort study. Infez Med. 2019;27:410-4.

78. Alfano G, Cappelli G, Fontana F, et al. Kidney disease in HIV infection. J Clin Med. 2019;8:1254.

79. van Wyk J, Ait-Khaled M, Santos J, Ajana F, et al. Brief report: improvement in metabolic health parameters at week 48 after switching from a tenofovir alafenamide-based 3- or 4-drug regimen to the 2-drug regimen of dolutegravir/lamivudine: the TANGO study. J Acquir Immune Defic Syndr. 2021;87:794-800.

80. McComsey GA, Kitch D, Daar ES, et al. Bone mineral density and fractures in antiretroviral-naive persons randomized to receive abacavir-lamivudine or tenofovir disoproxil fumarate-emtricitabine along with efavirenz or atazanavir-ritonavir: Aids Clinical Trials Group A5224s, a substudy of ACTG A5202. J Infect Dis. 2011;203:1791-801.

81. Cottrell ML, Hadzic T, Kashuba ADM. Clinical pharmacokinetic, pharmacodynamic and drug-interaction profile of the integrase inhibitor dolutegravir. Clin Pharmacokinet. 2013;52:981-94.

\section{Publisher's Note}

Springer Nature remains neutral with regard to jurisdictional claims in published maps and institutional affiliations. 